\title{
A CONSTRUÇÃO DO CAMPO DA EDUCAÇÃO MUSEAL: POLÍTICAS PÚBLICAS E PRÁTICA PROFISSIONAL
}

\section{THE CONSTRUCTION OF THE MUSEUM EDUCATION FIELD:} PUBLIC POLICIES AND PRACTICE

\section{LA CONSTRUCCIÓN DEL CAMPO DE LA EDUCACIÓN MUSEAL: POLÍTICAS PÚBLICAS Y PRÁCTICA PROFESIONAL}

Fernanda Santana Rabello de Castro ${ }^{1}$

\section{RESUMO}

Abordamos a construção da Política Nacional de Educação Museal a partir da análise do desenvolvimento das políticas públicas desse campo, no Brasil. Destacamos o aspecto participativo desse processo, liderado pelo Instituto Brasileiro de Museus, que contou com a atuação de educadores museais, professores, pesquisadores, estudantes e demais atores da sociedade civil e culminou no lançamento do Caderno da PNEM. Essa publicação apresenta-se como um marco na história da Educação Museal no Brasil, contendo textos que orientam e dão subsídios para o desenvolvimento de políticas, práticas e reflexões teóricas em torno da Educação Museal. A partir desse conteúdo apresentamos o Programa Educativo e Cultural, entendido como uma Política Educacional, documento sugerido pelos princípios da PNEM, como ferramenta de fortalecimento do campo, valorização de seus profissionais e desenvolvimento de boas práticas.

PALAVRAS-CHAVE: Educação Museal. Políticas Públicas. Programa Educativo e Cultural. Política Educacional.

\section{ABSTRACT}

We approached the construction of the National Policy on Muse- al Education based on the analysis of the development of public policies in this field in Brazil. We highlight the participatory aspect of this process, led by the Brazilian Institute of Museums, which was attended by museum educators, professors, researchers, students and other civil society actors and culminated in the launch of the PNEM Notebook. This publication presents itself as a milestone in the history of Muse- al Education in Brazil, containing texts that guide and give subsidies for the development of policies, practices and theoretical reflections around Muse- ern Education. From this content we present the Educational and Cultural Program, understood as an Educational Policy, a document suggested by the PNEM principles, as a tool for strengthening the field, valuing its professionals and developing good practices.

KEY WORDS: Museum Education. Public policy. Educational and Cultural Program. Educational politics.

Submetido em: 12/03/2019 - Aceito em: 08/04/2019 - Publicado em: 31/08/2019.

${ }^{1}$ Graduada em História (UFRJ), Mestre em Educação (UFRJ), Doutora em Educação (UFF). Técnica em assuntos educacionais no MHN/Ibram. Professora Convidada do Mestrado Profissional em História da UNIRIO e coordenadora do Grupo de Pesquisa Educação Museal: história, conceitos e política do diretório do IBRAM no CNPq. 


\section{RESUMEN}

Se aborda la construcción de la Política Nacional de Educación Museal a partir del análisis del desarrollo de las políticas públicas de ese campo, en Brasil. Destacamos el aspecto participativo de ese proceso, liderado por el Instituto Brasileño de Museos, que contó con la actuación de educadores museos, profesores, investigadores, estudiantes y demás actores de la sociedad civil y culminó en el lanzamiento del Cuaderno da. Esta publicación se presenta como un marco en la historia de la Educación Museal en Brasil, conteniendo textos que orientan y dan subsidios para el desarrollo de políticas, prácticas y reflexiones teóricas en torno a la Educación Museal. A partir de ese contenido presentamos el Programa Educativo y Cultural, entendido como una Política Educativa, documento sugerido por los principios de la PNEM, como herramienta de fortalecimiento del campo, valorización de sus profesionales y desarrollo de buenas prácticas.

PALABRAS CLAVE: Educación Museal. Políticas públicas. Programa Educativo y Cultural. Política Educativa.

\section{INTRODUÇÃO}

A Educação Museal vem sendo realizada como prática educacional específica e consolidando-se como campo de construção de conhecimento há mais de um século no Brasil. Fruto da ação profissional de educadores e das reflexões e políticas públicas de museus, vem-se fortalecendo por meio da avaliação e reflexão crítica sobre suas práticas, da elaboração de procedimentos, metodologias e ferramentas para seu desenvolvimento, além de estar constituindo-se desde a Política Nacional de Museus (PNM), de 2003, numa área específica de políticas públicas.

No seu campo específico, identificamos políticas públicas ora mais, ora menos estruturadas sendo criadas e implementadas desde o início do século XX, com destaque para iniciativas mais consolidadas a partir da década de 1980 e para uma efetiva política específica desenvolvida a partir de 2012, com a criação do Programa Nacional de Educação Museal e com a oficialização ${ }^{3}$ em 2017 da Política Nacional de Educação Museal (PNEM), dele derivada.

Uma das ferramentas sugeridas pela PNEM para contribuir com a consolidação e profissionalização do campo da Educação Museal é o Programa Educativo e Cultural (PEC), entendido como uma Política Educacional para a os museus e processos museais.

\footnotetext{
${ }^{3}$ A Portaria $n^{\circ} 422$ de 30 de novembro de 2017 publicada pelo Instituto Brasileiro de Museus oficializou a Política Nacional de Educação Museal, cinorporando seus princípios, diretrizes e elementos da Carta de Porto Alegre, documento elaborado durante o $2^{\circ}$ Encontro Nacional do Programa Nacional de Educação Museal. Seu conteúdo está disponível no Caderno da PNEM: < https://www.museus.gov.br/wpcontent/uploads/2018/06/Caderno-da-PNEM.pdf>.
} 


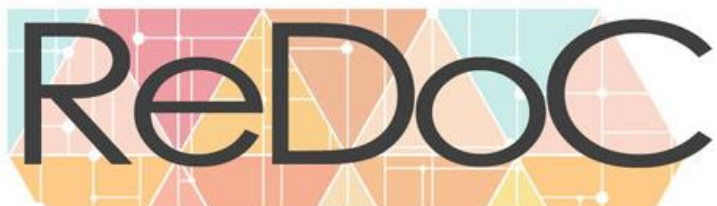

Revista Docência e Cibercultura

A seguir contextualizamos a construção do campo da Educação Museal no Brasil, bem como da origem da proposta de elaboração de uma política educacional a partir do processo de construção da PNEM. Apresentamos como a Política Educacional vem sendo trabalhada internacionalmente no campo da Educação Museal desde pelo menos a década de 1990 e como seu processo de elaboração aparece sugerido em publicações do Instituto Brasileiro de Museus (IBRAM).

\section{CONSTRUINDO A POLÍTICA NACIONAL DE EDUCAÇÃO MUSEAL}

Entre as políticas públicas específicas de educação museal, temos na década de 1980 uma primeira tentativa governamental organizada e continuada de implementação, com a criação do Programa Nacional de Museus (1980-1985), o Projeto Interação (1980-1985) e o Programa de Ação Cultural (1980-1985), que apresentaram propostas sistematizadas de projetos e modos de fazer e pensar a educação Museal, incluindo-se ferramentas, incentivo à formação profissional e integração entre cultura e educação na esfera das políticas públicas. Porém, o exemplo que representa maior elaboração e consolidação no campo tem sido o que resultou do Programa Nacional de Educação Museal, criado em 2012 pelo Instituto Brasileiro de Museus, que deu origem à Política Nacional de Educação Museal (PNEM).

A PNEM foi construída de forma participativa e democrática entre os anos de 2010 e 2017 e apresenta um conjunto de princípios e diretrizes que têm como objetivo orientar e subsidiar a ação educativa nos museus brasileiros. Os primeiros debates que culminaram na afirmação da necessidade de criação de uma política nacional para o campo surgiram no I Encontro de Educadores do Ibram, realizado no Museu Imperial, Petrópolis, em 2010, e geraram a publicação da Carta de Petrópolis.

Esse documento orientou a criação de conteúdos para o debate em nove Grupos Temáticos que formaram um Fórum Virtual para consulta pública, disponível no blog do Programa Nacional de Educação Museal, lançado em novembro de 2012, durante o $5^{\circ}$ Fórum Nacional de Museus, ocorrido também na cidade de Petrópolis.

A consulta pública ficou aberta entre novembro de 2012 e abril de 2013 e coletou propostas que depois de serem sistematizadas deram origem ao Documento Preliminar da PNEM, que passou a ter 10 grupos temáticos: Perspectivas Conceituais; Gestão; Profissionais de Educação Museal; Formação, capacitação e qualificação; Redes e parcerias; Estudos e pesquisas; Acessibilidade; Sustentabilidade; Museus e sociedade e Comunicação, este último tendo sido criado após a sistematização quando se viu que havia grande número de propostas que se relacionavam com essa temática. 
Após a realização da coleta de propostas no Fórum Virtual, os participantes cadastrados, juntamente com as Redes de Educadores em Museus (REM) de todo país, apresentaram a demanda de realizar encontros presenciais para discutir os conteúdos propostos. Sendo assim foram realizados 23 Encontros Regionais em que o Documento Preliminar da PNEM, tendo o seu conteúdo dividido entre diretrizes, estratégias e ações, recebeu adendos.

Formou-se então um grande documento, com análises e sugestões recebidas por todo território nacional que serviu de base para os debates realizados em dois Encontros Nacionais do Programa (ENPNEM) que tinham como objetivo definir uma Política Nacional de Educação Museal. O Documento Final da PNEM foi definido, contendo cinco princípios e 19 diretrizes, que trazem orientações para o desenvolvimento e consolidação do campo da educação museal. Foi necessário fazer-se um esforço de síntese e generalização que atendesse tanto a diversidade nacional dos processos educativos museais quanto desse conta dos principais problemas comuns a essas realidades.

Uma síntese do processo de construção da PNEM pode ser vista na figura a seguir:

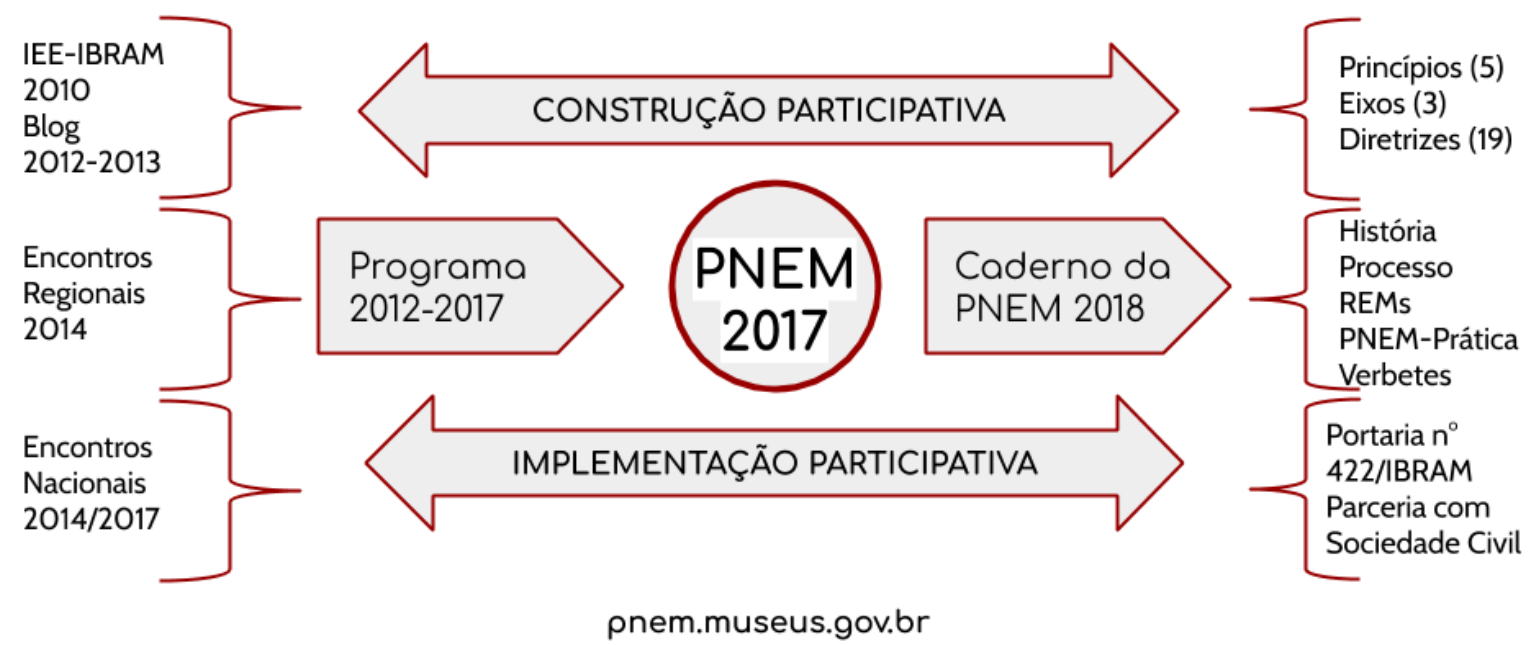

Figura 1 - Processo de Construção da Política Nacional de Educação Museal

Fonte: a autora.

Entre as propostas apresentadas durante o II ENPNEM, a Carta de Porto Alegre reafirmou a demanda dos participantes da construção da política acerca da necessidade de uma publicação que apresentasse os debates teóricos, conceituais e políticos que ocorreram no processo. Fruto dessa demanda foi elaborado o Caderno da Política Nacional de Educação Museal, que apresenta textos sobre: uma Breve história da educação museal no Brasil; o Processo de desenvolvimento da PNEM; A PNEM e as Redes de Educadores em Museus; A PNEM na prática: inspirações para educação museal; além de documentos de referência e de 13 verbetes que apresentam os termos e conceitos da educação museal, sendo eles (1) Acessibilidade Plena, (2) Comunidade, (3) Cultura digital, (4) Economia Solidária, (5) 


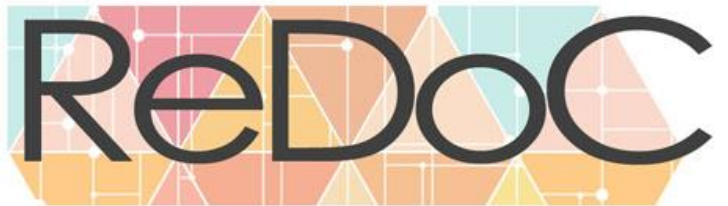

Revista Docência e Cibercultura

Educação Museal, (6), Educação Não Formal, (7) Formação Integral, (8) Mediação, (9) Museu Integral, (10) Planejamento Participativo, (11) Política Educacional, Missão Educativa, Programa Educativo e Cultural, (12) Públicos e (13) Sustentabilidade.

Podemos também sintetizar os processos e resultados que culminaram na criação da PNEM com o quadro abaixo, em que é possível perceber que a construção da política deu-se de forma participativa, com a atuação tanto do Ibram, órgão governamental, quanto da sociedade civil organizada e atores do campo da educação Museal.

\begin{tabular}{|c|c|c|c|}
\hline AÇ̃̃O & AGENTES & ANO & RESULTADOS \\
\hline $\begin{array}{l}\text { I Encontro de } \\
\text { Educadores do IBRAM }\end{array}$ & IBRAM e REM RJ & Julho de 2010 & Carta de Petrópolis \\
\hline $\begin{array}{l}5^{\circ} \text { FNM Lançamento do } \\
\text { Blog do Programa } \\
\text { Nacional de Educação } \\
\text { Museal }\end{array}$ & IBRAM & Novembro de 2012 & Fórum Virtual \\
\hline $\begin{array}{l}\text { Consulta pública no } \\
\text { Fórum Virtual do Blog } \\
\text { da PNEM }\end{array}$ & IBRAM & $\begin{array}{l}\text { Novembro de } 2012 \text { a } \\
\text { abril de } 2013\end{array}$ & $\begin{array}{l}\text { Propostas distribuídas em } \\
\text { nove Grupos temáticos }\end{array}$ \\
\hline $\begin{array}{l}\text { Sistematização das } \\
\text { propostas do Fórum } \\
\text { Virtual }\end{array}$ & IBRAM & Outubro de 2013 & $\begin{array}{l}\text { Documento Preliminar da } \\
\text { PNEM }\end{array}$ \\
\hline $\begin{array}{l}\text { Lançamento do } \\
\text { Documento Preliminar } \\
\text { da PNEM }\end{array}$ & IBRAM & Janeiro de 2014 & $\begin{array}{l}\text { Demanda por encontros } \\
\text { regionais presenciais }\end{array}$ \\
\hline Encontros Regionais & $\begin{array}{l}\text { IBRAM, REMs, } \\
\text { educadores, professores, } \\
\text { estudantes e demais } \\
\text { atores do campo }\end{array}$ & Março a outubro de 2014 & $\begin{array}{l}\text { Documento Preliminar } \\
\text { com adendos }\end{array}$ \\
\hline $\begin{array}{l}\text { I Encontro Nacional do } \\
\text { Programa Nacional de } \\
\text { Educação Museal }\end{array}$ & $\begin{array}{l}\text { IBRAM, REMs, } \\
\text { educadores, professores, } \\
\text { estudantes e demais } \\
\text { atores do campo }\end{array}$ & Novembro de 2014 & $\begin{array}{l}\text { Princípios da Política } \\
\text { Nacional de Educação } \\
\text { Museal } \\
\text { Carta de Belém }\end{array}$ \\
\hline $\begin{array}{l}\text { II Encontro Nacional do } \\
\text { Programa Nacional de } \\
\text { Educação Museal }\end{array}$ & $\begin{array}{l}\text { IBRAM, REMs, } \\
\text { educadores, professores, } \\
\text { estudantes e demais } \\
\text { atores do campo }\end{array}$ & Junho de 2017 & $\begin{array}{l}\text { Documento Final da } \\
\text { PNEM } \\
\text { Carta de Porto Alegre }\end{array}$ \\
\hline $\begin{array}{l}\text { Elaboração do Caderno } \\
\text { da PNEM }\end{array}$ & IBRAM e REMs & $\begin{array}{c}\text { Julho de } 2017 \text { a Maio de } \\
2018\end{array}$ & Caderno da PNEM \\
\hline
\end{tabular}

Quadro 1 Processo de desenvolvimento e resultados da Política Nacional de Educação Museal Fonte: a autora.

\section{A PNEM E O CONCEITO DE EDUCAÇÃO MUSEAL}

Entre as contribuições para o campo da educação Museal que originaram-se da PNEM destacamos a proposta de conceituação de educação museal, construída de forma participativa desde os primeiros debates do Programa, iniciada ainda no Fórum Virtual e que contou com 


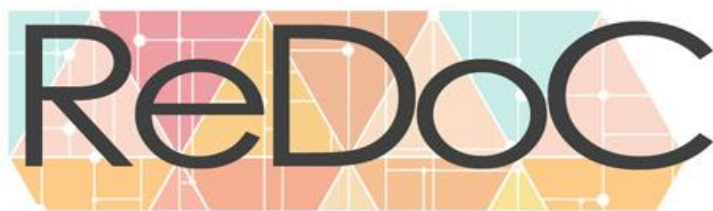

\title{
Revista Docência e Cibercultura
}

algumas versões antes de ser estabelecida no princípio 2 da PNEM da seguinte forma: "A educação museal compreende um processo de múltiplas dimensões de ordem teórica, prática e de planejamento, em permanente diálogo com o museu e a sociedade (IBRAM, 2017, p. 4).

Uma primeira definição conceitual da educação museal foi complementada no Caderno da PNEM com o verbete escrito por COSTA et. all (2018, p.73-74) que nos propõem que:

\begin{abstract}
A Educação Museal envolve uma série de aspectos singulares que incluem: os conteúdos e as metodologias próprios; a aprendizagem; a experimentação; a promoção de estímulos e da motivação intrínseca a partir do contato direto com o patrimônio musealizado, o reconhecimento e o acolhimento dos diferentes sentidos produzidos pelos variados públicos visitantes e das maneiras de ser e estar no museu; a produção, a difusão e o compartilhamento de conhecimentos específicos relacionados aos diferentes acervos e processos museais; a educação pelos objetos musealizados; o estímulo à apropriação da cultura produzida historicamente, ao sentimento de pertencimento e ao senso de preservação e criação da memória individual e coletiva. É, portanto, uma ação consciente dos educadores, voltada para diferentes públicos.

A Educação Museal coloca em perspectiva a ciência, a memória e o patrimônio cultural enquanto produtos da humanidade, ao mesmo tempo em que contribui para que os sujeitos, em relação, produzam novos conhecimentos e práticas mediatizados pelos objetos, saberes e fazeres. Possui também estrutura e organização próprias, que podem relacionar-se com outras realidades que não a específica dos museus, de acordo com os objetivos traçados no seu planejamento. São ações fundamentalmente baseadas no diálogo. Isso inclui o reconhecimento do patrimônio musealizado, sua apropriação e a reflexão sobre sua história, sua composição e sua legitimidade diante dos diversos grupos culturais que compõem a sociedade.

Neste contexto, a Educação Museal é uma peça no complexo funcionamento da educação geral dos indivíduos na sociedade. Seu foco não está em objetos ou acervos, mas na formação dos sujeitos em interação com os bens musealizados, com os profissionais dos museus e a experiência da visita. Mais do que para o "desenvolvimento de visitantes" ou para a "formação de público", a Educação Museal atua para uma formação crítica e integral dos indivíduos, sua emancipação e atuação consciente na sociedade com o fim de transformá-la. Vale ainda ressaltar que a Educação Museal, como processo museal e ação profissional específica, difere-se de ações de comunicação e de mediação cultural, por seus objetivos, metodologias e conteúdos próprios, porém sem deixar de ser necessário que seja integrada a essas práticas.
\end{abstract}

Surge como parte das ações de fortalecimento da educação museal como um campo de construção de conhecimento, a partir da proposição de um escopo teórico-conceitualmetodológico que apresentou também a necessidade de se pensarem ferramentas e procedimentos específicos para seu desenvolvimento e consolidação. Fruto de um acúmulo prático e político, a educação museal no Brasil tem-se constituído enquanto campo, assim como proposto por Boudieu (1976) e já tendo proposta conceitual já desenvolvida em 


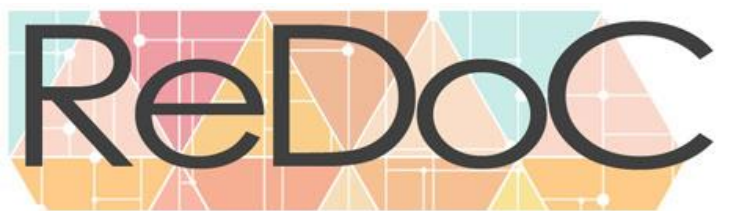

\section{Revista Docência e Cibercultura}

trabalhos nacionais (LIMA, 2018; CASTRO, 2018) e enquanto proposta teórico conceitual no seu próprio fazer crítico.

A proposta de conceituação da educação museal construída na PNEM diferencia-se de outras noções de educação pré-existentes nos campos do patrimônio e da memória por colocar no centro da ação educativa museal o indivíduo e a necessidade de sua formação, emancipação e atuação crítica na transformação da sociedade.

Entre as ferramentas e processos necessários à consolidação desse campo, o Programa Educativo e Cultural, entendido a partir dos debates da PNEM como uma Política Educacional, é um instrumento que representa um avanço que vem fortalecer ainda mais o campo e seus debates.

\section{O Programa Educativo e Cultural como Política Educacional}

Pensado para ser um documento denso, referenciado no Plano Museológico de cada instituição, tendo como base de elaboração a avaliação das condições estruturais do trabalho educativo nos museus, seus recursos e suas concepções de educação, essa ferramenta permitirá que ações de planejamento, sistematização, registro e avaliação de programas, projetos e ações educativas museais sejam realizadas garantindo a memória e o legado institucional na área educativa dos museus. A constituição dessa memória institucional é um passo fundamental na consolidação da formação dos profissionais do campo e também da qualificação das suas práticas e reflexões educativas.

Tais ações, de planejamento, sistematização, registro e avaliação do trabalho educativo em museus vêm sendo desenvolvidos no campo já há algumas décadas, destacadamente em países europeus e nos EUA, onde conseguimos encontrar algumas referências que sugerem modelos de elaboração.

Eilean Hooper-Greenhill, educadora e pesquisadora inglesa, da Universidade de Leicester, organizou em 1991 uma publicação intitulada Writing a museum education policy, em que se apresentam diretrizes para elaboração de uma Política Educacional para museus. São identificadas áreas que precisam ser consideradas no seu desenvolvimento, ressaltando-se que cada instituição tem uma política única, que deve ser elaborada de acordo com seus recursos e objetivos. 


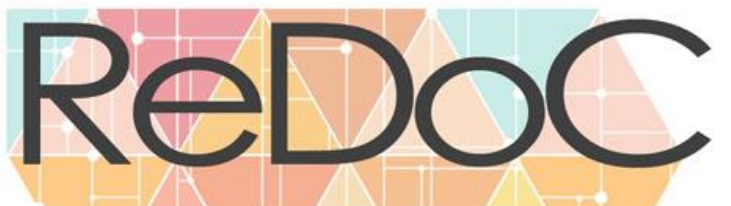

Revista Docência e Cibercultura

Destaca-se que criar uma política educacional institucional não significa necessariamente aumentar a oferta de ações que um museu pode ter (a não ser que esse seja o objetivo), mas sim criar um foco e direcionar esforços já existentes.

Entre os benefícios de uma política educacional são listados:

- Aumentar a satisfação profissional

- Aprimorar os serviços

- Atrair novos visitantes

- Poupar tempo (estabelecendo prioridades claras)

- Promover um programa educacional mais nitidamente focado

- Atrair apoio de fora para o trabalho do museu

- Elevar o perfil do museu (HOOPER-GREENHILL, 1991, p.8) [tradução nossa].

Apresentando uma definição, a publicação aponta que uma política deve:

- definir objetivos que possam ser facilmente indicados aos órgãos governamentais

- promover um contexto para tomada de decisões

- identificar prioridades que a equipe pode usar na tomada de decisões

- identificar tarefas

- ser suficientemente precisa para permitir que se desenvolva avaliação (HOOPER-GREENHILL, 1991, p.8) [tradução nossa].

Indica-se ainda que a política define a característica da instituição e deve ser elaborada com o diálogo entre dirigentes e equipes responsáveis pelo trabalho educativo das instituições. Ressalta-se que pode ser necessário realizar pesquisas e que a política educacional deve ser endossada pelo corpo dirigente do museu, o que é algo já pressuposto, se pernsarmos em uma elaboração participativa e dialógica.

De acordo com a proposta que consta entre as diretrizes de Wrinting a museus education policy, o documento final da política educacional deve conter:

- a afirmação da missão educacional: que deve se adequar à missão do museu como um todo e deve explicar tanto como a "educação" é entendida no museu, quanto o papel da educação no museu

- a política educacional: que define as instenções da organização e identifica prioridades

- $\quad$ estratégias educacionais: que identificam objetivos chave para um período de cinco a dez anos 


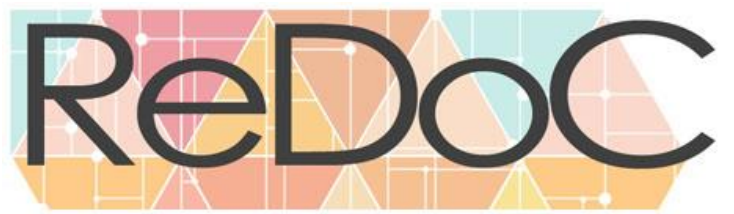

Revista Docência e Cibercultura

- o plano de ação educativa: que é um programa a ser desenvolvido entre dois a cinco anos, permitindo esses objetivos serem alcançados (HOOPERGREENHILL, 1991, p.9) [tradução nossa].

Entre os conteúdos a serem considerados numa política educacional estariam: audiências; recursos/ despesas; tipos de suprimentos; papéis e funções dentro dos museus; redes fora dos museus; formação; publicidade e avaliação.

Dentre esses, destacamos o papel e funções da educação dentro do museu, como apontadas:

\begin{abstract}
As necessidades educativas devem ser abordadas como uma questão em termos de decisões administrativas, incluindo a alocação de recursos, publicidade, loja e publicações. O planejamento de exposições é uma área particularmente vital em que a educação pode oferecer uma contribuição; níveis de linguagem, densidade de exposições, níveis de leitura, nexos com o currículo e espaço para aulas e para grupos nas galerias devem ser considerados.

A educação também pode monitorar e contribuir para questões de acesso e informação, incluindo sinalização e instalações para os visitantes com necessidades especiais, incluindo pessoas com deficiência e pessoas com bebês e crianças pequenas. O planejamento da gestão deve incluir a formação para todo o pessoal, incluindo aqueles que trabalham na educação; em alguns casos, funcionários da educação atuam como agentes de formação para o museu.

Onde o pessoal da educação está empregado, a representação nos compromissos apropriados e a ligação com outros funcionários do museu facilitarão a atenção aos assuntos educacionais. Recursos adequados devem ser permitidos para possibilitar isso. Onde não há pessoal especializado em educação, um indivíduo específico deve ser responsável tanto por questões de monitoramento que tenham implicações para a educação, quanto por procurar aconselhamento apropriado fora do museu, conforme necessário (HOOPER-GREENHILL, 1991, p.11) [tradução nossa/ grifo nosso].
\end{abstract}

Dois pontos cruciais são levantados: a necessidade de valorização da educação museal por meio da previsão de recursos estáveis para realização de suas ações e a integração do educador museal nos diversos processos e setores dos museus, com poder de levar as questões educativas para todo museu.

Destaca-se também a preocupação com a realidade diversa encontrada em diferentes tipos de museus. É sabido que muitos não possuem nem setores educativos, nem profissionais de educação museal. Nesse contexto sugere-se que o trabalho educativo seja responsabilidade de um profissional que busque formação específica e apoio interinstitucional. 


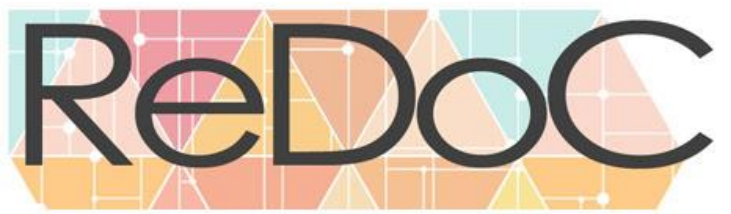

\title{
Revista Docência e Cibercultura
}

Na publicação propõe-se também que uma política educacional não pode existir no vácuo e deve relacionar-se com outras políticas e estratégias institucionais, além de outras políticas temáticas terem que considerar questões educativas.

Graeme K. Talboys (2005, p. 41), trata também do assunto no livro Museum Educator's Handbook (Manual dos Educadores Museais), em que aborda a construção de políticas educacionais para museus sustenta igualmente que:

Dado que um museu tem ou deseja oferecer um serviço de educação através dos serviços de um educador museal, é melhor que isso seja estabelecido em uma política oficial de educação escrita, apoiada por uma descrição do trabalho e um plano de ação. Dentro do museu, esses documentos cumprem várias funções importantes.

Eles:

- definem as metas e objetivos de um serviço de educação;

- fornecem um contexto no qual esse serviço possa operar e desenvolver-se;

- fornecem uma estrutura dentro da qual seja possível identificar tarefas específicas programas de trabalho;

- permitem uma visão geral a partir da qual seja possível avaliar a importância relativa dos projetos e definir prioridades; - definir diretrizes que auxiliem na tomada de decisões; e - codificar expectativas, recursos disponíveis e grupos de usuários, permitindo a realização de uma avaliação precisa [tradução nossa].

Além de reforçar as sugestões apresentadas por Hooper-greenhill et. al., ainda na década de 1990, Tallboys (2005, p.41) indica outras necessidades de que derivam as políticas educacionais institucionais:

\begin{abstract}
Muito além das razões internas perfeitamente válidas para produzir uma política educacional, há também razões externas convincentes. Pode ser o caso, por exemplo, que produzir e a implementação de uma política educacional é exigida pelos órgãos que financiam o museu. Aumento demandas de responsabilidade pública significam que a forma como o dinheiro (especialmente alocado e gasto é monitorado de perto. Outros fundos, especialmente doações e patrocínios, é mais provável que seja alocado a um museu que possa demonstrar que tem estrutura administrativa como políticas em vigor.

Políticas, declarações e avaliações também têm um papel importante a desempenhar para outros (dentro e fora do museu) que você é um profissional, que o que você faz é baseado em princípios sólidos e formalmente acordados. Grupos de usuários educacionais em em particular, estão à procura de tais provas quando decidem se devem ou não utilizar museu [tradução nossa].
\end{abstract}

Podemos acrescentar a essa lista a orientação ou exigência do poder público sobre a necessidade de criação de políticas educacionais institucionais, como dá-se no Brasil a partir da oficialização da PNEM. Tallboys atenta ainda para o fato de que, uma vez que a política 


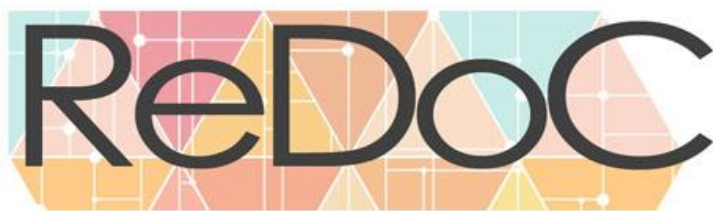

\title{
Revista Docência e Cibercultura
}

educacional está instituída e aprovada pela gestão da instituição, é muito mais difícil ela sofrer interferências ou descontinuidade.

No contexto das motivações e justificativas para elaboração de políticas educacionais para museus, Timothy Ambrose (2006, p. 60) coloca ainda que:

\begin{abstract}
Programas ativos de eventos informais e atividades que apoiam a missão do museu são um meio poderoso de construir apoio para o museu. Eventos e programas de atividades - físicos e virtuais - podem afetar significativamente a percepção do público sobre o museu e ajudam a desenvolver o interesse do mercado. Programas de eventos e atividades podem ser desenvolvidos para melhorar os serviços que o museu oferece e para atender às necessidades de públicos-alvo específicos ou segmentos de mercado. Organizando eventos e programas de atividades dentro do próprio museu, no local ou on-line, são uma abordagem. Outra abordagem é para o museu organizar atividades em outros locais, talvez em parceria com outras instituições ou organizações, e assim desenvolver novas audiências para o museu e seu trabalho.

Em muitos casos, esses eventos e atividades podem gerar renda e também atrair apoio financeiro por meio de doações e patrocínios e, assim, importantes vertentes de renda adicional para o museu. A decisão sobre quais eventos e atividades oferecer gratuitamente e quais eventos e atividades cobrar é uma decisão política para o museu fazer [tradução nossa].
\end{abstract}

Sobre essa afirmação destaca-se uma visão institucional de gestão realizada com foco ou em parceria com o "mercado", muito comum em países estrangeiros, que cada vez mais ganha espaço no cenário museal brasileiro a despeito de sua viabilidade, eficácia e compromisso pedagógico questionáveis. Apesar disso, o que o autor apresenta é que a política institucional pode utilizar-se do trabalho educativo para aumentar a receita da instituição bem como atrair setores interessados em nichos específicos de mercado ou em publicidade cultural. Essa visão deve então constar da política educacional institucional, caso seja do interesse do museu, de forma coerente às concepções de educação assumidas.

Tallboys (2005, p.42) quando trata da elaboração da política educacional, sobre seu processo diz também que:

O primeiro passo no sentido de promover uma política para a educação é assegurar que a educação é mencionada especificamente na política geral do museu. Se não houver menção, ou o menção for vaga, então vale a pena fazer lobby para existir uma menção ou que seja mais específica. Além disso, qualquer declaração sobre educação deve ser redigida de tal modo que a educação seja reconhecida como parte essencial e integrante do museu. A noção de integração é extremamente importante. A política de educação deve aumentar as metas e objetivos dos programas de pesquisa do museu, gerenciamento de coleções, formação de pessoal, políticas de exposição e conservação, concepção e angariação de fundos, bem como trabalhando por direito próprio. A educação dos museus deve, portanto, ser planejada, 
desenvolvida e implementado em conjunto com os objectivos e objectivos claramente definidos contidos no política geral do museu [tradução nossa].

O autor apresenta uma proposta de estruturação da política educacional que deve conter uma política primária, uma política secundária e um plano de ação:

Quando a declaração está sendo elaborada, deve haver uma clara diferenciação entre política primária (uma declaração geral de princípios - que deve caber confortavelmente em uma folha de papel), política secundária (uma explicação desses princípios) e a ação plano (uma descrição dos programas que derivam da política) (TALLBOYS, 2005, p.42) [tradução nossa].

Fazendo um paralelo com o que tem-se desenvolvido no Brasil nesse sentido, pode-se pensar numa estrutura em que se apresente sinteticamente: (1) a missão educacional ${ }^{4}$, seguida de seus objetivos e princípios, (2) uma parte mais densa em que são apresentados os referenciais teóricos, o diagnóstico, os perfis de público, estabelecidas prioridades e apresentados os programas, projetos e ações da instituição e por fim a apresentação de diretrizes, estratégias, ações e metas.

Com o objetivo de auxiliar no processo de elaboração do documento da política educacional Tallboys (2005, p.43) segue apresentando sugestões de forma e conteúdo e ressalta a importância de construção de um texto claro e objetivo, destacando que:

\begin{abstract}
Embora seja essencial que o documento final seja claro em seu significado, ele deve ser mais que um conjunto de diretrizes. Certifique-se de que não há nada que não precise estar lá. Pela mesma razão, não inclua nada muito específico. Documentos de política não são o lugar para isso.

Tudo o que entra em um documento de política tem implicações de longo prazo para o trabalho do educador do museu e o serviço que eles poderão oferecer. É importante estar ciente de quais poderiam ser essas implicações e como elas afetariam o trabalho da educação do museu nos anos vindouros [tradução nossa].
\end{abstract}

Considerando a necessidade de planejamento das ações que integrarão os programas previstos na política educacional institucional, Tallboys (2005, p.44) afirma que alguns dos pontos cruciais a serem considerados são: o financiamento das ações, o espaço disponível para executá-las, as formas de avaliação e a questão das concepções e definições, que o autor

\footnotetext{
${ }^{4}$ Missão educacional é o termo utilizado por Luciana Martins no caderno da PNEM para explicar o que é e como se orienta a elaboração da missão educativa do museu. (MARTINS, 2018, p.96)
} 


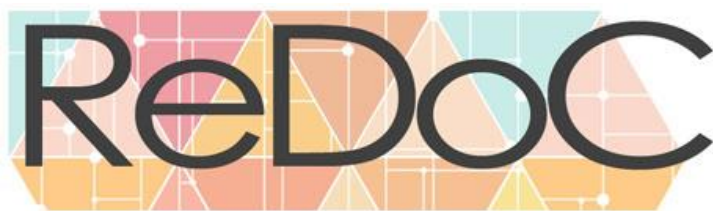

Revista Docência e Cibercultura

atenta como sendo uma das dificuldades a ser encarada no que diz respeito à integração da proposta educativa com a política mais geral das instituições:

O que são os significados de "educação", "educação de museu", "educador de museu" e assim por diante? Isto é extremamente importante, não apenas como um exercício para garantir que esses termos sejam bem definidos, mas também para assegurar que as definições sejam entendidas e acordadas pela gestão do museu. Não é bom, afinal, escrever uma política educacional se quem a ratifica tem idéia completamente diferente do que se entende por educação para a pessoa que realmente coloca a política em prática [tradução nossa].

O autor segue propondo que constem na política educacional a descrição das atribuições dos profissionais e dos programas, projetos e ações, de forma clara e precisa. Destaca também que em situações em que não haja profissionais e equipes, o papel educativo da instituição deve ser indicado mesmo assim, bem como as ações desenvolvidas no âmbito da educação.

Em seguida apresenta a necessidade de criação de um Plano de Ação. Após definir concepções, diretrizes, atribuições e tarefas, faz-se necessário explicitar como o conteúdo da política educacional será implementado.

A construção do Plano de Ação é o momento de pensar em programas, projetos e ações e de se fazer um planejamento detalhado: o que se quer fazer? por que? como? o que se tem de recursos para atingir objetivos específicos? quais as dificuldades? quais as vantagens? as perspectivas? metas...

Nesse estágio é imprescindível lançar mão de um diagnóstico da situação da instituição, apoiado em estudos de público, realizar processos de sistematização, registro e criar indicadores e ferramentas de avaliação. Nem tudo o que for produzido integrará o documento final da política educacional instituição. Projetos, ementas de programas, materiais de apoio poderão ser elaborados, ou mesmo podem-se aproveitar recursos e planejamentos já existentes, que deverão ser indicados como material anexo, ou leitura indicada.

Em Como gerir um museu: manual prático, publicação do Conselho Internacional de Museus, Cornelia Brüninghaus-Knubel, a então Directora do Departamento da Educação, Wilhelm Lehmbruck Museum, Duisburg, Alemanha, pensando a elaboração de programas e de uma política institucional sugere-se que:

Com o cada museu é diferente, o pedagogo do museu, em consulta com os colegas da curadoria, precisam de fazer algum as perguntas básicas ao analisar e planear o serviço educativo. Estas diferirão de acordo com as circunstâncias, mas podem incluir: 
Relativamente à situação geográfica:

1. Serve um a com unidade grande ou pequena?

2. O ambiente envolvente é urbano, industrial ou rural?

3. O museu relaciona-se de forma eficaz, com a sua situação geográfica?

Relativamente à estrutura social e cultural da população:

4. Como serão os visitantes potenciais?

5. Quais os visit ant es e outros utilizadores que querem os que venham ao museu e porquê?

6. Quais são as tradições culturais da comunidade: podem ser ligadas aos objectivos e políticas do museu?

7. Quais são os problem as contemporâneos com que a comunidade tem de lidar?

Relativamente a aspectos museológicos:

8. Quais são as características fundamentais das colecções?

9. Quais são as suas origens? 10. Quais são as obrigações do museu para com entidades externas, como o Estado, cidade, outras entidades financiadores ou doadores?

Relativamente a finanças:

11. Quais as fontes de financiamento disponíveis especificamente para o trabalho educativo?

12. Qual a utilização mais eficaz do orçamento disponível para a educação do museu disponível? (BRÜNINGHAUS-KNUBEL, 2004, p.132).

Tais questões nos auxiliam a refletir sobre o contexto em que se insere o museu e como elas podem influenciar o desenvolvimento de ações educativas, ideias necessárias para se pensarem as diretrizes, estratégias, programas, projetos e ações que constarão na política educacional.

A autora nos apresenta um esquema elaborado por Eilean Hooper-Greenhill, na publicação Museums and Gallerie Education, de 1991, para pensar a estruturação de programas educativos: 


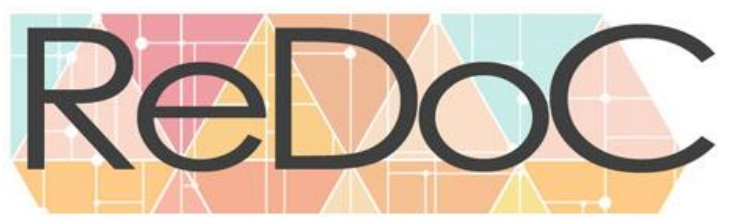

Revista Docência e Cibercultura

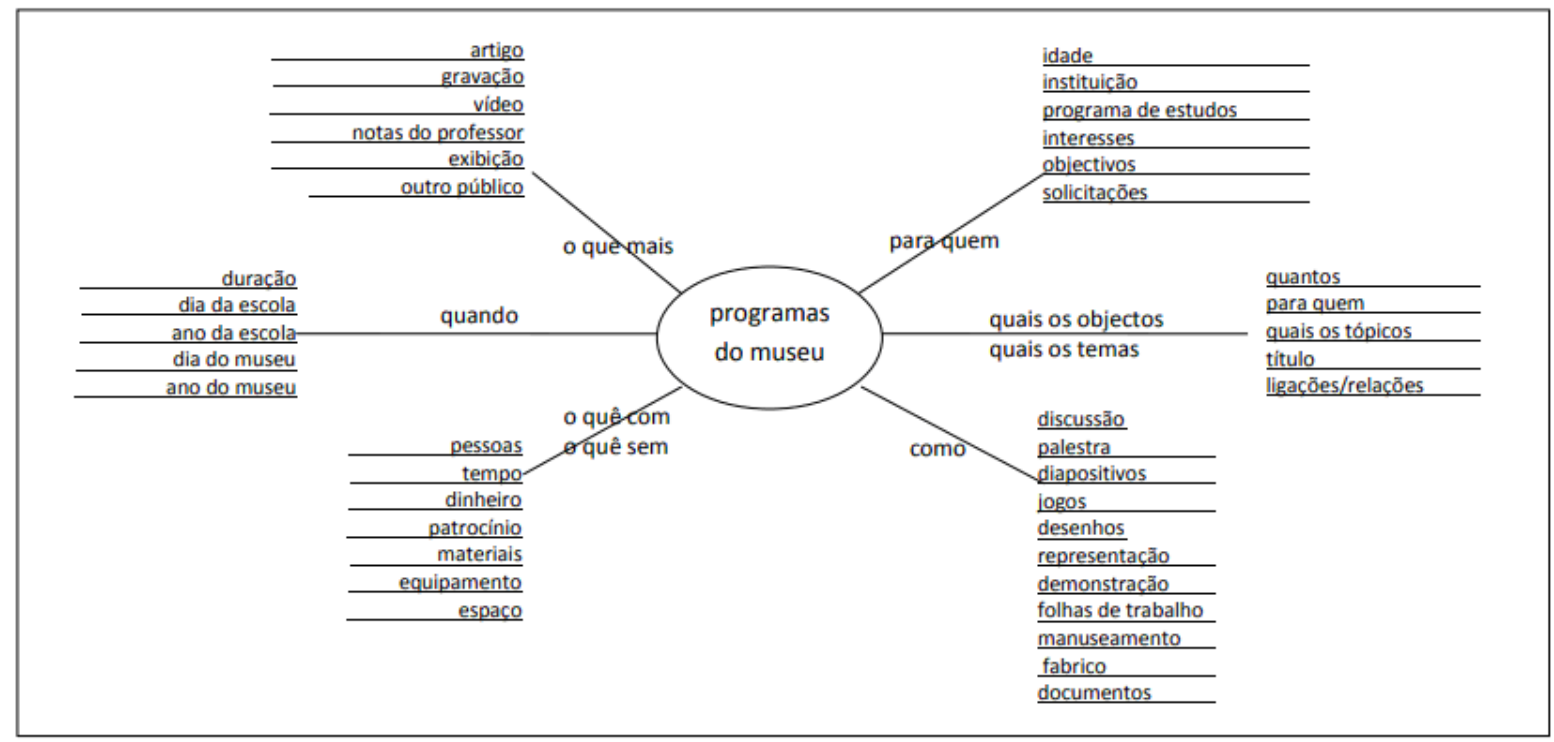

Figura 2. Programas do museu

Fonte:[HOOPER-GREENHILL, Elilean. Museums and galleries education, apud BRÜNINGHAUS-KNUBEL, 2004, p.133]

Percebemos que sugere-se um esquema detalhado de como pensar em programas que podem compor a política educacional a partir da definição de públicos-alvo, estabelecimento de metodologias, levantamento de recursos (inclusive temporais), definição de produtos, de equipe e parceiros e com quais objetivos.

Na publicação seguem-se exemplos de como elaborar ações educativas, de tipos de atividades e de materiais geralmente produzidos e utilizados em ações educativas museais.

A criação ou manutenção de uma base de dados e/ou arquivo de memória, que podem ser físicos ou digitais são algumas das atribuições e das premissas do trabalho educativo. Sua previsão deve constar na política educacional e os recursos necessários devem ser priorizados para que se aumente o caráter profissional do trabalho educativo, que permitirá a criação de um legado e memória institucional. Nesse momento vale a pena atuar em parceria com outros setores ou profissionais do museu, como arquivos históricos ou institucionais, bibliotecas, quando existirem.

Mais uma publicação que pode servir de referência para a construção de políticas educacionais ou mesmo apenas para projetos e ações é um manual elaborado pelo Ministério da Educação, Cultura e 
Desporto da Espanha: Projetos educativos e culturais em museus - Guia básico de planejamento 5 . Elaborada a partir do documento Best practice. Education and cultural action programmes. Analyzing a program, desenvolvido pelo Comitê Internacional de Educação e Ação Cultural (CECA), a publicação foi desenvolvida pelo Laboratório Permanente de Público de Museus da Espanha.

Dividido em quatro capítulos o guia apresenta um passo a passo para o desenvolvimento de projetos, explicando cada ponto a ser levado em consideração no que diz respeito à: Concepção; Planejamento e Produção; Execução do projeto (com proposta de avaliação a ser realizada ao longo das ações) e Avaliação Final.

\section{Concepción del proyecto}

Se trata de la fase de conceptualización del proyecto, fundamentalmente reflexiva. En ella debe redactarse un documento (anteproyecto) claro y conciso que recoja los siguientes puntos:

\subsection{Origen}

Se trata de las razones o elementos iniciadores del proyecto (principalmente ideas, pero también situaciones o personas) que promueven el mismo. Si el motor del proyecto es una idea, esta debe estar bien definida, ser realista en relación a nuestros recursos y transformadora (debe provocar algún tipo de cambio).

\subsection{Diagnóstico}

El proyecto debe partir de una evaluación de necesidades o diagnóstico cuyo objetivo es conocer el alcance de un problema y sus características esenciales para poder hacerle frente. Para ello se suele recurrir a la utilización de datos estadísticos, censos y datos de otros programas, encuestas de población, opinión de expertos, técnicas de grupo, paneles delphi o foros.

\subsection{Justificación}

En esta fase identificaremos las condiciones sociales, económicas, etc., en las que se va a desarrollar el proyecto y argumentaremos por qué es necesario y cuáles son las razones que nos llevan a plantearlo.

- Social

El museo está situado en un contexto social del cual es inseparable; la relación entre este contexto y el proyecto es la justificación social. El proyecto debe tener en cuenta principios de igualdad, inclusión, respeto a la diversidad y participación, entre otros.

Figura 3. Projetos educativos e culturais em museus - Guia básico de planejamento Fonte: [MINISTERIO DE EDUCACIÓN, CULTURA Y DEPORTE, 2015, p.6].

\footnotetext{
${ }^{5}$ Disponível na página do ministério: <https://sede.educacion.gob.es/publiventa/d/20194C/19/1>.
} 


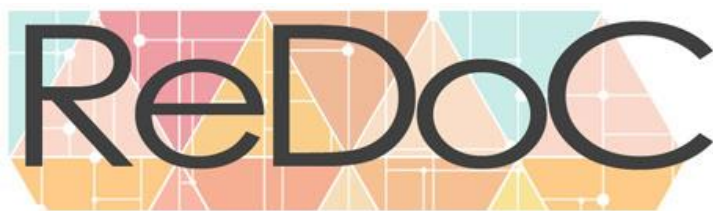

\section{Revista Docência e Cibercultura}

No Brasil são poucos os casos de autores que trabalharam até agora na produção de propostas sistematizadas de elaboração de políticas educacionais para museus. Podemos encontrar exemplos de ferramentas de gestão já implementadas e avaliadas, como no caso dos setores educativos dos museus da Secretaria de Cultura e Economia Criativa do Estado de São Paulo, que possui toda uma sistematização e conjunto de contratos e ferramentas de gestão que inclui o Programa Educativo e Cultural como uma política educacional.

$\mathrm{Na}$ Revista Musas $\mathrm{n}^{\circ}$ 4, Cristina Carvalho (2009) relata a experiência de participar da construção do Plano Educacional da Fundação Casa de Rui Barbosa, destacando elementos do processo como a necessidade de pesquisa histórica e diagnóstica, realização de conversas com os setores da instituição e valorização das ações já realizadas, a criação de ferramentas de pesquisa, planejamento e avaliação, o desenvolvimento de metodologias e, mais que tudo, a escolha de concepções de educação e cultura que permeiem e orientem a elaboração de uma política educacional em acordo com os anseios institucionais e em diálogo com a sociedade.

Nacionalmente temos também produções recentes do Instituto Brasileiro de Museus que contribuem para se pensar a elaboração de políticas educacionais, programas, projetos e ações educativas de museus, como veremos a seguir.

\section{A PNEM e as Políticas Educacionais institucionais}

Como a proposição de elaboração de uma política educacional institucional relaciona-se com as políticas públicas de museus no Brasil?

Apesar de alguns documentos e normatizações do âmbito da política pública Museal terem avançado no sentido de reconhecer a função educativa dos museus, a legislação da área apenas tangencia a questão da educação museal, não apresentando regulamentações ou obrigatoriedades práticas. No Estatuto de Museus, a Lei n 11.904/2009, a educação aparece na Subseção II, do Estudo, da Pesquisa e da Ação Educativa, do Capítulo II, Do Regime Aplicável aos Museus, da seguinte forma:

Art. 28. O estudo e a pesquisa fundamentam as ações desenvolvidas em todas as áreas dos museus, no cumprimento das suas múltiplas competências.

$\S 1$ - O estudo e a pesquisa nortearão a política de aquisições e descartes, a identificação e caracterização dos bens culturais incorporados ou incorporáveis e as atividades com fins de documentação, de conservação, de interpretação e exposição e de educação.

$\S 2$ 2。 Os museus deverão promover estudos de público, diagnóstico de participação e avaliações periódicas objetivando a progressiva melhoria da qualidade de seu funcionamento e o atendimento às necessidades dos visitantes. 


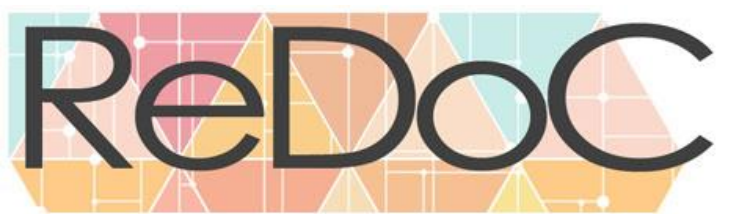

Revista Docência e Cibercultura

Art. 29. Os museus deverão promover ações educativas, fundamentadas no respeito à diversidade cultural e na participação comunitária, contribuindo para ampliar o acesso da sociedade às manifestações culturais e ao patrimônio material e imaterial da Nação.

Art. 30. Os museus deverão disponibilizar oportunidades de prática profissional aos estabelecimentos de ensino que ministrem cursos de museologia e afins, nos campos disciplinares relacionados às funções museológicas e à sua vocação (BRASIL, 2009).

Podemos perceber que o conteúdo relativo à educação museal na legislação de museus é bem genérico, não apresentando especificidades acerca da elaboração de uma política educacional específica.

Na seção III, do mesmo capítulo que trata Plano Museológico, essa ferramenta é apresentada como a seguir:

Art. 45. O Plano Museológico é compreendido como ferramenta básica de planejamento estratégico, de sentido global e integrador, indispensável para a identificação da vocação da instituição museológica para a definição, o ordenamento e a priorização dos objetivos e das ações de cada uma de suas áreas de funcionamento, bem como fundamenta a criação ou a fusão de museus, constituindo instrumento fundamental para a sistematização do trabalho interno e para a atuação dos museus na sociedade (BRASIL, 2009).

Entre os programas que devem ser desenvolvidos no Plano Museológico está o Programa Educativo e Cultural. O atual modelo seguido pelo Ibram para elaboração desse programa indica a criação de diretrizes, estratégias, ações e metas, mas não na forma de um documento destacado e sim como parte integrante da política institucional global.

O Programa Educativo e Cultural, como proposto pela PNEM, sendo um documento específico, baseado no Plano Museológico, mas desenvolvido a parte dele, entendido como uma política educacional tem seu escopo sugerido no Caderno da Política Nacional de Educação Museal (2018). Além dessa publicação, que foi fruto do processo participativo de construção da PNEM, o Ibram possui ainda outra, anterior a sua definição, em que se apresenta uma proposta de elaboração do PEC como parte dos programas do Plano Museológico: Subsídios para elaboração de Planos Museológicos (2016). Seus objetivos são assim expressos:

oferecer subsídios para a elaboração de Planos Museológicos pelos museus brasileiros, atuando como geradora de conhecimento e formação para a área museológica, fomentando tanto a formação e a qualificação de profissionais e estudiosos da área, quanto as normas e os procedimentos para a organização da 


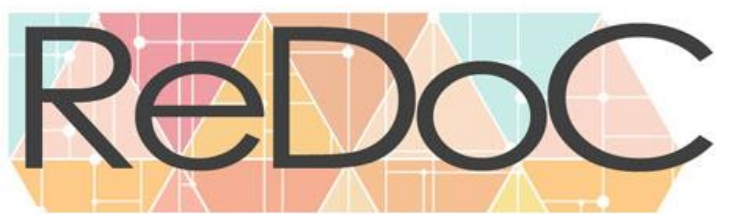

Revista Docência e Cibercultura

gestão e do planejamento dos museus por meio da disponibilização de subsídios técnicos (IBRAM, 2016, p. 6).

Essa produção técnica, portanto, oferece orientações e subsídios que permitem aos museus brasileiros pensar sua estruturação técnica a partir de suas práticas e especificidades, já que:

A estrutura proposta na legislação, ainda que na forma de recomendação, destaca a possibilidade e adequação de diferentes realidades. $O$ setor museal tem características próprias, que o distingue na área da cultura, pois nenhum museu é igual a outro. Isso implica proporcionar uma visão crítica que auxilie a construção de planos museológicos adequados às diferentes realidades, uma vez que cada instituição possui sua forma de organização e construção de identidade. Afinal, cada instituição pode estar em funcionamento ou em fase de criação, pertencer ao setor público ou privado e ter ou não experiência de planejamento estratégico (...)

O Plano Museológico deve ser elaborado com a finalidade de orientar a gestão do museu e estimular a articulação entre os diversos setores de funcionamento, tanto no aprimoramento das instituições museológicas já existentes, quanto na criação de novos museus. Essa ferramenta de planejamento estratégico deve ordenar e priorizar as ações a serem desenvolvidas pelo museu para o cumprimento da sua função social e constituir-se como um documento museológico que baliza a trajetória do museu.

(...)

No entanto, o Plano Museológico não é apenas um plano estratégico. A legislação nos indica um conjunto de programas, que correspondem a diferentes atividades que integram a gestão de museus. O Plano Museológico traz elementos de planejamento tático, isto é, do planejamento relativo ao nível gerencial da organização. Os programas delimitam grandes áreas e os projetos que os compõem indicam o que fazer para que os objetivos estratégicos sejam atingidos. (IBRAM, 2016, p. 35-36).

É nesse contexto que vemos as orientações para construção do Programa educativo e Cultural que deve abranger "os projetos e as atividades educativo-culturais desenvolvidos pelo museu, destinados a diferentes públicos e articulados com diferentes instituições" (IBRAM, 2016, p. 36).

Do mesmo modo que vemos ser apresentado nas publicações estrangeiras aqui mencionadas, a publicação do Ibram (2016, p. 37) traz um alerta no que:

diz respeito ao caráter interdisciplinar dos programas. Por exemplo, o Programa Educativo pode ter reflexos no Programa de Gestão de Pessoas, caso demande capacitação ou novos servidores, ou no Programa de Financiamento e Fomento, caso precise de investimentos, ou no Programa de Comunicação, caso necessite de difusão para a comunidade ou escolas. O Estatuto de Museus prevê, ainda, que os projetos tenham um cronograma de execução e que sejam desmembrados em ações, o que se aproxima de um planejamento operacional. No caso dos museus públicos, é 


\section{Revista Docência e Cibercultura}

preciso articular o Plano Museológico com o plano anual prévio, conforme observamos anteriormente. É recomendado que o Plano Museológico seja elaborado de forma participativa, envolvendo os funcionários do museu e outros atores relevantes, como representantes da comunidade, associação de amigos, professores ou representantes de atividades econômicas que se relacionem com o museu, por exemplo. Também se recomenda a avaliação permanente e a revisão periódica, com a temporalidade definida no regimento interno. A legislação, no entanto, não especifica o período a ser abrangido pelo plano, embora se sugira o prazo de cinco anos como um prazo razoável para implementação das ações.

São sugeridas, como num manual prático, a realização de algumas etapas para elaboração do Plano Museológico: (I) Caracterização, planejamento conceitual, diagnóstico e objetivos estratégicos; (II) Programas e (III) Elaboração de projetos no Plano Museológico. É justamente quando se trata dos projetos a serem desenvolvidos que o PEC aparece, com delineamento de concepções de educação e de museu:

A partir das discussões acerca do trabalho com a memória e a cultura, que culminaram na Mesa Redonda de Santiago do Chile, em 1972, e seus desdobramentos, a educação museal assume um novo compromisso com a realidade social e com as transformações contemporâneas. A proposta político-pedagógica do museu deve ser fundamentada no respeito à diversidade cultural e na construção participativa e democrática do conhecimento. Segundo essa concepção, as ações educativas em museus têm o objetivo de construir uma educação comprometida com a transformação social. No processo de aprendizagem, não basta saber o que são os bens musealizados do museu, é preciso compreender seu contexto social junto a uma consciência crítica e abrangente da realidade que o cerca (IBRAM, 2016, p. 64) [grifo nosso].

Sobre a metodologia de elaboração do PEC, sugere-se ainda que:

É importante a elaboração participativa do programa, em que a equipe do museu, a partir da perspectiva dos diferentes setores - museologia; educativo e cultural; comunicação; pesquisa; arquivo; biblioteca; expografia; imagem institucional, etc.-, e também de seus parceiros e da comunidade, compreendam qual a concepção de educação que se pretende e como ela será expressa nas suas atividades (IBRAM, 2016, p. 65) [grifo nosso].

Após orientações gerais, segue-se para a instrumentalização necessária para elaborar o PEC, afirmando que a estrutura e formato do podem ser diversas, bem como sua metodologia de elaboração, mas que é importante considerar alguns itens imprescindíveis ao programa, sendo eles: o diagnóstico; o estudo dos públicos; os projetos e os indicadores e instrumentos de avaliação. 


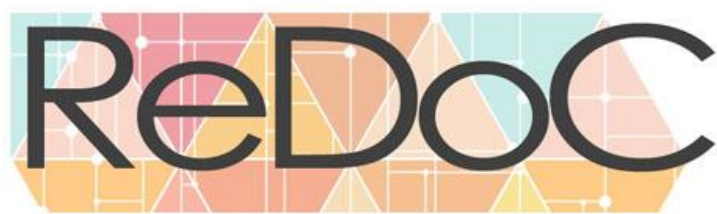

\section{Revista Docência e Cibercultura}

Sugerem-se algumas questões a serem abordadas na produção de um diagnóstico institucional sobre o trabalho educativo, que dizem respeito à concepção das ações, à execução das ações, à avaliação e aos resultados das ações e à relação museu-comunidade e à relação museu-escola.

Salienta-se a necessidade de o museu, ao pensar o Programa Educativo e Cultural, começar considerando a diversidade de públicos, elencando projetos e ações já realizadas, listando ferramentas e atividades e pensando em indicadores e instrumentos de avaliação. A esse respeito coloca-se que:

O Programa Educativo e Cultural e cada projeto individualmente precisam, ao fim do processo, passar por uma fase de avaliação, momento em que se analisa se os objetivos foram alcançados e quais resultados foram obtidos com a realização das ações, respondendo-se às seguintes perguntas: Chegamos aos resultados esperados? Alcançamos o que queríamos fazer? Se não, por quê? Mas para que se possa fazer uma avaliação final, é preciso - antes de realizar a ação, no momento do planejamento - prever como medir os objetivos esperados e como averiguar se foram alcançados. (...)

Para conferir se o indicador foi alcançado, é preciso ter um instrumento de verificação (IBRAM, 2016, p. 70-71).

É importante lembrar que os indicadores de avaliação são elaborados de acordo com os objetivos educativos apresentados no PEC, que por sua vez são pensados a partir das concepções de educação e das ferramentas teóricas e metodológicas elencadas pelas equipes de profissionais, de acordo com os recursos de que a instituição dispõe.

Um elemento importante que não é abordado nesta publicação, porém é o da pesquisa em educação museal. Essa que é uma das funções educativas do museu, produzir conhecimento, é comumente delegada a setores de pesquisa, ou a pesquisadores que não são educadores, quando existem. Não considerar os próprios educadores como produtores de conhecimento prático, teórico e metodológico sobre o seu trabalho limita as possibilidades de reflexão e melhoria das ações educativas, bem como diminui a função educativa do museu.

Já a PNEM apresenta o Programa Educativo e Cultural em outros marcos. Entende-o como um documento a parte do Plano Museológico, não autônomo, mas elaborado a partir das diretrizes educacionais que nele constam, porém mais detalhadamente desenvolvido.

O PEC aparece na PNEM já como um dos seus cinco princípios, como vemos a seguir:

4 Cada museu deverá construir e atualizar sistematicamente o Programa Educativo e Cultural, entendido como uma Política Educacional, em consonância ao Plano 


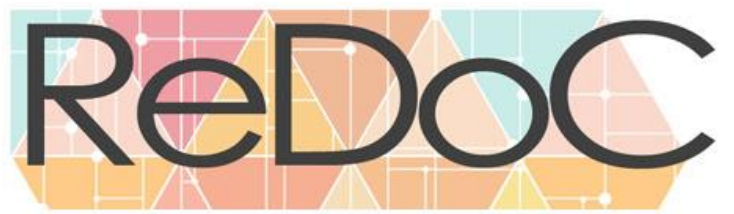

\title{
Revista Docência e Cibercultura
}

Museológico, levando em consideração as características institucionais e dos seus diferentes públicos, explicitando os conceitos e referenciais teóricos e metodológicos que embasam o desenvolvimento das ações educativas (IBRAM, 2017, p.4) [grifo nosso].

O Documento apresenta a seguir diretrizes distribuídas em três eixos, abordando o PEC em dois deles. No Eixo I - Gestão, sugere-se:

\begin{abstract}
1 Incentivar a construção do Programa Educativo e Cultural, entendido como uma Política Educacional, definido a partir da missão do museu, pelo setor de educação museal, em colaboração com os demais setores do museu e a sociedade.

2 Promover o desenvolvimento do Programa Educativo e Cultural no Plano Museológico e estabelecer entre suas atribuições: missão educativa; referências teóricas e conceituais; diagnósticos de sua competência; descrição dos projetos e plano de trabalho; registro, sistematização e avaliação permanente de suas atividades e formação continuada dos profissionais do museu (IBRAM, 2017, p.5) [grifo nosso].
\end{abstract}

Temos então dois momentos e dois PECs diferentes e complementares: o programa que deve ser parte do Plano Museológico e o PEC, entendido como política educacional, que deve ser um documento elaborado a parte, em consonância com o Plano Museológico, com maior densidade e aprofundamento pedagógico.

Observemos que na diretriz 2, destacada acima, estão listadas algumas das atribuições dos profissionais de educação museal. As questões relacionadas ao debate acerca da profissionalização dos educadores, à definição de suas funções e ao detalhamento do PEC, aparecem de forma mais elaborada nos princípios 2 e 3 do Eixo II - Profissionais, formação e pesquisa da PNEM:

2 Reconhecer entre as atribuições do educador museal: a atuação na elaboração participativa do Programa Educativo Cultural; a realização de pesquisas e diagnósticos de sua competência; a implementação dos programas, projetos e ações educativas; a realização do registro, da sistematização e da avaliação dos mesmos; e promover a formação integral dos indivíduos.

3 Fortalecer o papel do profissional de educação museal, estabelecendo suas atribuições no Programa Educativo e Cultural em conformidade com a Política Nacional de Educação Museal (IBRAM, 2017, p. 6).

Temos então que a elaboração do PEC está estreitamente ligada à discussão sobre a necessidade de profissionalização do campo da educação museal. Entre os desafios colocados nesse contexto para a elaboração do PEC, conforme sugerido pelas publicações do Ibram, destacam-se a situação dos museus de pequeno porte e de museus que não possuem setores 


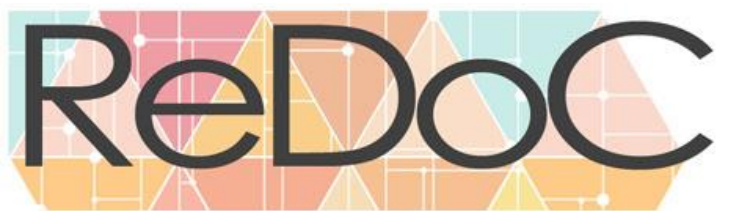

\section{Revista Docência e Cibercultura}

educativos, museus fechados para visitação e ou que possuem público reduzido ou pouco variado.

No sentido de tornar menos complexa e mais exequível a tarefa de elaboração do PEC, o Caderno da PNEM traz a seguinte premissa:

Conceber o Programa Educativo e Cultural desde o início pode parecer uma tarefa impossível. Muitas vezes o linguajar da área educacional não é familiar e pensar em objetivos pedagógicos ou avaliações parecem tarefas escolarizadas, distantes do universo museal. Mas, ao partirmos da premissa de que o papel social dos museus é educacional, baseamo-nos em uma noção contemporânea de educação, na qual os processos pedagógicos são dialogados e o conhecimento é construído coletivamente. Levar em consideração essas premissas é fundamental na construção do programa educativo e cultural dialógico, tanto pela equipe do museu ou processo museológico quanto pela sociedade.

Para que o Programa Educativo e Cultural seja feito de uma forma participativa, o primeiro passo é a escuta dos envolvidos no processo. Por meio da escuta é possível acessar as experiências, as percepções e os pensamentos dos sujeitos envolvidos nas ações do Programa Educativo e Cultural do museu. (IBRAM, 2018, p.47).

No Caderno da PNEM também ressalta-se a importância de se elaborar o PEC a partir de uma concepção pré estabelecida de educação, que leve em consideração a missão educativa do museu, expressa em seu Plano Museológico.

A partir daí então pode-se pensar nos elementos que devem constar no PEC, que nessa publicação são assim listados, sendo em seguida explicados: diagnóstico; referências teóricas e conceituais; sujeitos/ públicos; missão educativa; objetivos educacionais; ação educativa; sustentabilidade e financiamento; profissionais; registro, sistematização e avaliação.

A publicação apresenta ainda definições e exemplos de programas, projetos e ações, inclusive de projetos premiados por boas práticas e que já são realizados conforme as sugestões que foram elaboradas na PNEM.

\section{CONSIDERAÇÕES FINAIS}

A consolidação da educação museal como um campo profissional, de prática, de pesquisa e de produção de conhecimento e fazendo parte das funções essenciais dos museus é um processo que vem ganhando cada vez mais espaço no universo museal. 


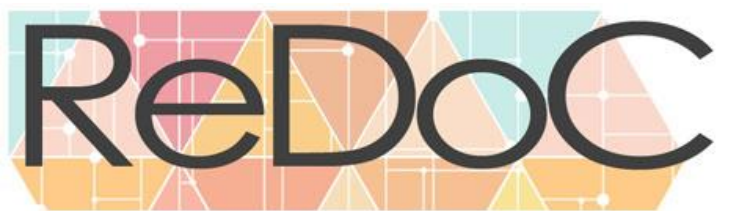

\section{Revista Docência e Cibercultura}

O desenvolvimento de políticas públicas específicas a esse campo, no contexto das políticas públicas de museus tem fortalecido e tornado cada vez mais profissionais suas ações, complexificando-as e aumentando o número de metodologias, abordagens, ferramentas e reflexões sobre a prática educativa museal.

A PNEM apresentou um conjunto de princípios e diretrizes que já são tomados como exemplo e base para o desenvolvimento, avaliação e reestruturação das práticas e elaborações teóricas do campo, sugerindo ferramentas e procedimentos que vêm sendo desenvolvidos de maneira cada vez mais profissional.

O PEC, entendido como uma Política Educacional, é uma das ferramentas mais importantes e essenciais a ser elaborada nesse contexto. Abordamos nesse artigo algumas das referências e possibilidades de construção desse documento, que podem contribuir para o seu pensar e fazer nos mais diferentes contextos existentes no diverso mundo dos museus e processos museais.

Entre as sugestões mais significativas destacamos a necessidade de elaboração de um documento, preferencialmente de forma participativa e integradas com os demais setores do museu e com a sociedade, destacado do Plano Museológico, mas nele embasado, que apresente concepções de educação, referenciais teóricos e metodológicos, objetivos de atuação, diagnósticos, perfis de público, prioridades de atuação, levantamento de desafios e que descreva os programas, projetos e ações institucionais, suas ferramentas e recursos e as atribuições dos profissionais neles envolvidos.

O PEC assim entendido e elaborado é em si uma sistematização do trabalho educativo e deve prever formas de registro e avaliação, que permitam a construção de legados institucionais e de uma memória educativa dos museus e processos museais. Aprovado pela gestão do museu, revisto e atualizado periodicamente, pode ser tanto o documento fundante do trabalho e de setores educativos, quando peça fundamental para sua reestruturação e profissionalização.

O PEC em si não é um instrumento mágico de solução de problemas, mas todo processo que envolve sua concepção e a reflexão em torno das práticas educativas institucionais, sejam elas educativas ou não, auxiliam na implementação da PNEM e reforçam a função educativa do museu, sua missão social e papel na transformação da sociedade.

\section{REFERÊNCIAS}

AMBROSE, Timothy; PAINE, Crispin. Museum basics. Abingdon: Routledge, 2006. BOURDIEU, P. Le champ scientifique. Actes de Ia Recherche en Sciences Sociales, n. 2/3, jun. 1976, p. 88-104. Tradução de Paula Montero. Disponível em: < 
https://cienciatecnosociedade.files.wordpress.com/2015/05/o-campo-cientifico-pierrebourdieu.pdf $>$. Acesso em 11 de junho de 2019.

BRÜNINGHAUS-KNUBEL, Cornelia. A Educação do Museu no Contexto das Funções Museológicas. In: ICOM. Como gerir um museu: manual prático. Paris, ICOM, 2004. p. 129-144.

CARVALHO, Cristina. Cultura: conceitos aplicados a espaços culturais. In: Revista Musas, n 4, 2009, p.132-147, Brasília: IPHAN.

COSTA et. all. Educação Museal. In: Caderno da PNEM. Brasília: Ibram, 2018. p. 73-77

HOOPER-GREENHILL, Eilean et. all. Writing a museum education policy. Leicester:

Leicester University press, 1991.

IBRAM. Caderno da Política Nacional de Educação Museal. Brasília: Ibram, 2018.

IBRAM. Documento Final da PNEM. Brasília: Ibram, 2017.

IBRAM. Subsídios para elaboração de planos museológicos. Brasília: Ibram, 2016.

BRASIL. Legislação sobre museus [recurso eletrônico] : Lei n ${ }^{\circ} 11.904$, de 14 de janeiro de 2009, que institui o Estatuto de Museus, Lei $\mathrm{n}^{\circ} 11.906$, de 20 de janeiro de 2009, que cria o Instituto Brasileiro de Museus (Ibram), e legislação correlata. - 3. ed. - Brasília : Câmara dos Deputados, Edições Câmara, 2017. Disponível em:

<http://bd.camara.gov.br/bd/handle/bdcamara/14599>. Acesso em: 8 mar. 2019. LIMA, Isabel Victória Van Der Lay. O estágio em museus de ciência: O Museu como Espaço de Produção do Conhecimento e Formação. Tese de Doutorado. Programa de Pós Graduação em Educação - PUC-RJ. 2018. Disponível em: <http://www.gepemci.com.br/wpcontent/uploads/2018/04/Tese-Isabel-Lima.pdf>. Acesso em: 11 de março de 2019.

MARTINS, Luciana Conrado. Política Educacional, Missão Educativa, Programa Educativo e Cultural. In: Caderno da PNEM. Brasília: Ibram, 2018. p.93-98.

MINISTERIO DE EDUCACIÓN, CULTURA Y DEPORTE. Proyectos educativos y culturales en museos - Guía básica de planificación. Madrid: Secretaría General Técnica, 2015.

TALLBOYS, Graeme K. Museum educator's handbook. Burlington: Ashgate Publishing Company, 2005. 